\title{
Simulating Land-Cover and Land-Use Change in the Savanna Under Present Day and Future Climate Scenarios-A GIS-Based Approach
}

\author{
Mayowa J. Fasona ${ }^{1}$, Alabi S. Soneye ${ }^{1}$, Olatunde J. Ogunkunle ${ }^{1}$, Olusegun A. Adeaga ${ }^{1}$, Olutoyin A. Fashae ${ }^{2}$ \& \\ Innocent I. Abbas ${ }^{3}$ \\ ${ }^{1}$ Department of Geography, University of Lagos, Lagos, Nigeria \\ ${ }^{2}$ Department of Geography, University of Ibadan, Ibadan, Nigeria \\ ${ }^{3}$ Department of Geography, Ahmadu Bello University, Zaria, Nigeria \\ Correspondence: Mayowa J. Fasona, Department of Geography, University of Lagos, Lagos, Nigeria. Tel: \\ 234-802-312-7998. E-mail: mfasona@yahoo.com
}

Received: July 26, $2013 \quad$ Accepted: August 13, $2013 \quad$ Online Published: December 6, 2013
doi:10.5539/esr.v3n1p25
URL: http://dx.doi.org/10.5539/esr.v3n1p25

\begin{abstract}
Understanding the feedback between climate and land-cover is important for planning climate mitigation and adaptation measures at local scales. This study presents evidence that climate change has the potential to influence land-cover patterns over space and time and land change models can compliment climate models to provide better understanding of the climate and land-cover relations at local levels. Present day (1982-2006) and downscaled future (2046-2065) rainfall and temperature data were integrated with local eco-geographical factors to build change suitabilities for land-cover change for present day and future climate scenarios. The basis land-cover maps were derived from Landsat imageries. The change suitabilities were combined with markov probabilities and applied to the basis land-cover to predict future land-cover maps under the present day and future climate scenarios using Idrisi's Cellular Automata-Markov land change model. The results suggest that forest and woodland which is the major canopy ecosystems are expected to remain relatively stable both in areal coverage and spatial pattern under the present day climate scenario. In the future climate scenario, the areal coverage of the canopy ecosystems is expected to be relatively stable, but dramatic change in the spatial pattern is likely as the wooded savanna becomes drier. The forests would likely become more disturbed, with galleria forest becoming the most significant forest type. Shrub/grassland is also projected to become much more widespread. This scenario is expected to alter the spatial pattern of emerging built up and agricultural land-uses.
\end{abstract}

Keywords: GIS, land-cover, climate change, cellular automata-markov, savanna, Nigeria

\section{Introduction}

Land-use and land-cover (LULC) change which refers to modification or replacement of cover types represents an index of significant natural and anthropogenic disturbance to ecosystems. It is important in the global change process particularly with respect to the climate systems (Neigh, Tucker, \& Townshend, 2008; Li, Ma, Xu, Wang, \& Zhang, 2009; Hoffman \& Jackson, 2000). The relationship between climate and terrestrial ecosystems is characterized by a two-way feedback. While much is now known about the possible impacts of land-cover change on the climate system (Taylor, Lambin, Stephenne, Harding, \& Essery, 2002; Abiodun, Pal, Afiesimama, Gutowski, \& Adedoyin, 2008), the potential of the climate to influence land-cover change across space and time has not received considerable attention (Hely et al., 2006; Hoffman \& Vogel, 2008). This latter part of the interaction needs to be better understood in the context of the requirements for local climate mitigation and space and context-specific adaptation measures.

Solomon et al. (2007) suggested that land-cover changes may have positively influenced the pre-industrial climate. On the other hand, the general increase in temperature and decline in rainfall that have characterized the present climate are projected to have negative impacts on land-cover. This also posed the possibility of climate becoming a strong driver of future ecosystem changes and biodiversity (Leary, Kulkarni, \& Seipt, 2007, German Advisory Council on Climate Change, 2008). The potential impact of vegetation on climate is becoming better established in land surface climatology studies. Sensitivity experiments conducted using general circulation models (GCMs) and regional climate models (RCMs) at global to sub-regional scales often use simple to 
moderate land-cover change assumptions. However, they have provided insights into the dynamics of land-atmosphere interactions and potential impacts on temperature, rainfall, wind, albedo, etc (see MacKellar, Tadross, \& Hewitson, 2009; Wang \& Eltahir, 2000; Nicholson, 2000; Taylor et al., 2002; Abiodun et al., 2008; Li et al., 2009). The coarse spatial resolution of some of the models often masks large differentials in the actual gradient and other characteristics of land-cover types. Some assumptions of large scale changes in vegetation are often unrealistic because vegetation and land-cover changes tend to occur in complex, heterogeneous patches across space. Many impact applications, including local mitigation and adaptation actions, require the equivalent of local-scale observations. They are very sensitive to fine-scale climate variations that are parameterized at a coarse scale in climate models (Wilby et al., 2004; Hewitson \& Crane, 2006).

However, climate models have generally addressed one side of the feedback. There are very few studies on changes in the land-cover over time and across space in response to changing climate. A good knowledge of the human drivers of LULC change (such as resource use decisions including agriculture, logging, and wood extraction at local levels) and the ecogeographical factors that drive the local climate system is important for understanding land-use and cover dynamics across space under a changing climate. Some of these local drivers may be difficult to parameterize in climate models with coarse resolutions. Geographic information system (GIS) and remote sensing (RS) can generate and effectively integrate local ecogeographical factors and resource use decisions in modelling LULC change. GIS and RS can also provide feedbacks that can be incorporated into place and context specific adaptation planning. The integration of GIS and RS can, therefore, effectively compliment climate models in understanding the impacts of the climate on land-cover change especially at local levels.

We argue in this paper that land change models developed through the integration of GIS and RS data can potentially compliment climate models in providing insight into climate and land-cover relations across space and time. We also argue that changing land-cover pattern in response to the climate has the possibility to trigger spatial reorganization in the pattern of settlement and agrarian land-uses across space and time in poor small-holder, rainfed agrarian landscapes. In the sahel and savannas where agriculture is predominantly rainfed, rainfall decline has been hypothesized to have strong negative effect on LULC change (Hoffmann \& Jackson, 2000; Omotosho \& Abiodun, 2007). The aim of this study is to demonstrate that the pattern of land-cover changes in the wooded savanna will follow different trajectories in response to changes in rainfall and temperature under the present day and future climate scenarios.

The basis land-cover (1986 and 2006) was derived from Landsat imageries. Markov probability matrices and conditional probabilities of change for each land-cover category were generated from the basis land-cover. Local ecogeographical factors (including derivatives from terrain, soil and population) were combined with mean historical rainfall and temperature data (1982-2006 which represents present day climate) and downscaled rainfall and temperature data (2046-2065 which represents future climate) to build change suitability maps for each land-cover category. Two sets of change suitabilities - one for present day climate and another for the future climate - were prepared. The suitability maps were applied to the basis land-cover maps and the conditional probabilities of change to simulate the land-cover under the present day and the future climate scenarios. The simulation was carried out using Idrisi's dynamic Cellular Automata-Markov land change model.

\section{Materials and Methods}

\subsection{Regional Setting}

The study area is roughly defined by Latitudes $8^{\circ}$ to $9^{\circ} 15^{\prime}$ North and Longitudes $3^{\circ} 50^{\prime}$ to $5^{\circ} 50^{\prime}$ East. It covers about $40,000 \mathrm{~km}^{2}$ in western Nigeria, extending from the border with Benin Republic in the west to the Niger floodplains in central Nigeria covering parts of Oyo, Kwara, Kogi, Niger, Ekiti and Osun States (Figure 1). 


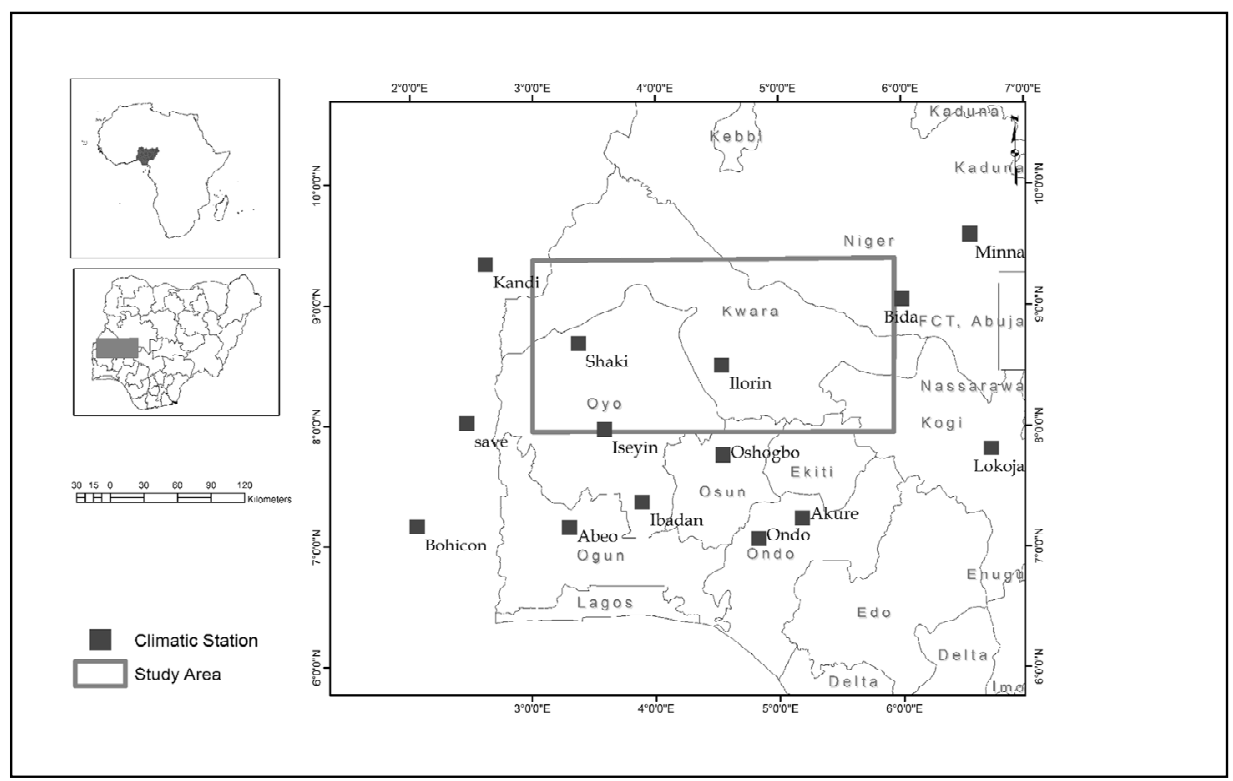

Figure 1. The study area

The study area is covered by the wooded savanna ecology which approximates the transitional zone between the southern rainforest and the northern grassland savanna. Average elevation is about $300 \mathrm{~m}$ but with outcrops rising above $500 \mathrm{~m}$ in the eastern axis. Vegetation consists of mixture of trees and grasses, as well as moist peri-forest mixed with savanna of anthropic degradation and patchy landscape (Hoffmann \& Jackson, 2000; Bucini \& Lambin, 2002). Generally, the area is characterized by a sub-humid Koppen's $A w$ climate (Kottek, Grieser, Beck, Rudolf, \& Ru, 2006). Annual rainfall received falls between $900 \mathrm{~mm}$ and $1300 \mathrm{~mm}$ and mean maximum temperature range is between $28{ }^{\circ} \mathrm{C}$ and $36{ }^{\circ} \mathrm{C}$ with peak temperature occurring around February and March. The southern part shares the bimodal rainfall pattern of the southern rainforest belt with peaks in mid June to July and September. The highest monthly rainfall occurs in September as opposed to July for the rainforest belt. Monsoonal wind and mesoscale convective processes (MCS) are the dominant rain producing forces over the region. The MCS predominates and produces over $75 \%$ of rainfall received (Omotosho \& Abiodun, 2007).

Population density is high, the ecosystem contributes significantly to human well-being and poverty-environment linkage is very strong. Survival for large rural population depends on small-holder rainfed agriculture (Odekunle, Balogun, \& Ogunkoya, 2005; Afiesimama, Pal, Abiodun, Gutowski, \& Adedoyin, 2006; Fasona, Omojola, Adeaga, \& Dabi, 2007) and root, tuber and cereal cultivation is common.

\subsection{Data Utilized}

\subsubsection{Satellite Imagery and Terrain Data}

Six georeferenced and orthorectified Landsat scenes (p190r054 of 15 November 1986, p191r054 of 27 December 1990, p190r054 of 13 November 2000, p191r054 of 06 February 2000, p190r054 of 14 November 2006, and p191r054 of 18 November 2005) were accessed from Landsat Geocover datasets (www.landcover.org/data/). Terrain derivatives, including slope, aspect, contours, and spot heights, were generated from Shuttle Radar Topography Mission (SRTM) three-arc-second digital elevation model data (SRTM_ffB03, p190r054 and p190r054) downloaded from Global land cover archives (http://www.land cover.org/data/srtm/).

\subsubsection{Present and Future Climate}

Data for historical daily rainfall and maximum temperature (Tmax) from 1982-2006 for 12 climatic stations around the study area and adjacent stations in Benin Republic (see Figure 1) were acquired from the archives of the Nigerian Meteorological Agency (NIMET) and the portal of the Climate Systems Analysis Group (CSAG), University of Cape Town (www.csag.uct.ac.za) respectively. Statistical downscaling of the data was carried out by CSAG. The statistical downscaling technique employed matching of GCM data with self organized map (SOM) characterization of atmospheric states and was forced by an SRES A2 emissions scenario (Hewitson \& 
Crane, 2006). The driving GCMs employed were adopted from the Coupled Model Intercomparison Project Phase Three (CMIP3) archive (http://www.pcmdi.llnl.gov/projects/cmip/Table.php), which makes statistical downscaling possible only for the non-seamless periods of 2046-2065 (near future) and 2081-2100 (far future). The statistical downscaling reproduced the observational data and produced both near-future and far-future projections for $10 \mathrm{GCMs}$ and NCEP reanalysis. A comparability study of GCMs carried out by Cook and Vizy (2006) suggested that the Japanese MRI CGCM 2.3.2 model provides the most reliable simulation of the twenty-first century climate over West Africa. The downscaled data from MRI CGCM was adopted for input into the land change modeling.

\subsubsection{Other Dataset}

Other datasets used include the 1:650,000 scale soil data produced by the Soils Survey Division of the Nigerian Ministry of Agriculture and Natural Resources and the 1:250,000 Vegetation and Land use data produced in 1995/96 by the Forestry Resources Mapping, Evaluation and Coordination Unit (FORMECU) of the same Ministry. Population data were obtained from the archive of the Nigerian National Bureau of Statistics.

\subsection{Procedure}

\subsubsection{Framework}

The methodology used follows an inductive approach in which spatial datasets for climate, LULC and human activity are analyzed to generate first-level results, which become data inputs for higher order analyses that produce integrated results (Figure 2). This approach is necessary because several spatial data layers need to be analyzed and different change drivers generated. The change drivers were integrated to build land change or suitability maps that are applied to the image-derived land-cover data to project future land-cover maps.

The Landsat images bands 7, 4 and 2 were subjected to band compositing using Idrisi ${ }^{\circledR}$ Taiga software (www.clarklabs.org). A land cover classification schema derived from the USGS land-use/land-cover schema (Anderson, Hardy, Roach, \& Witmer, 1976) was developed through a process that includes the collation of land -cover signatures during field reconnaissance, accumulation of spectral signatures that ensure inter-image consistency, and modification of the classification schema of the existing 1:250,000 Vegetation and Land use data.

The maximum likelihood (MAXLIKE) classification algorithm was adopted because the training sites were well defined with large sample sizes. MAXLIKE is a hard classifier that assigns pixels to the most likely class based on a comparison of the posterior probability that it belongs to each of the signatures being considered (Weng, 2002; Eastman, 2009). Refinement and modification of the classification outputs led to a reduction of the initial 25 categories to a final 13 categories (see Table 2). The output was subjected to a Markovian probability estimator to generate conditional probabilities for the prediction of future land-cover change. Change drivers, including present and future rainfall and Tmax, soil potential for agriculture, protected area, population density, elevation, slope, and aspect were used as factor inputs to build composite change suitability maps using multi-criteria analysis. The combination of the suitability maps and land-cover-derived Markov conditional probability maps were the input for the Cellular Automata-Markov (CA-Markov) model. 


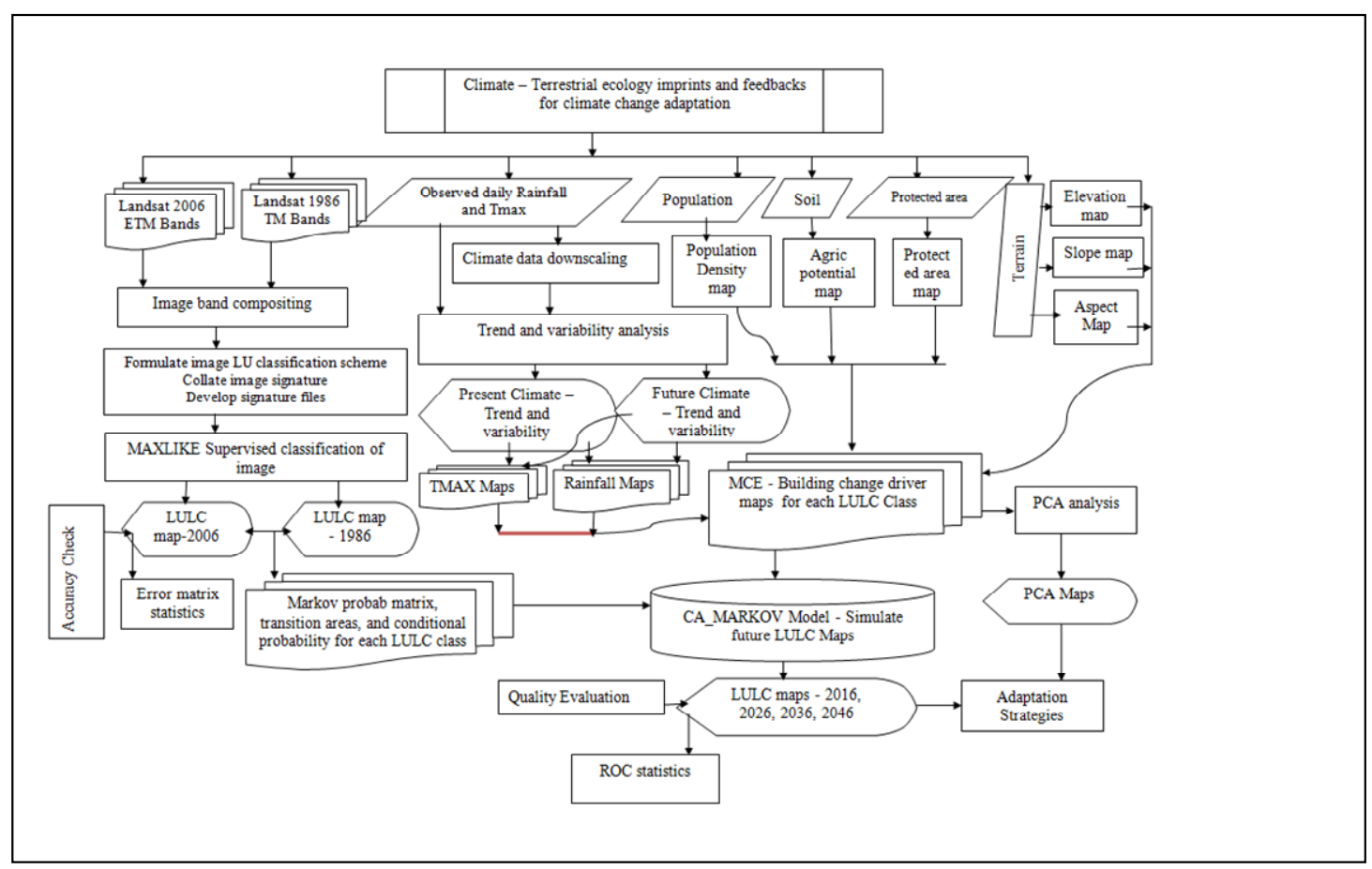

Figure 2. Methodological framework

\subsubsection{Model Description and Experimental Set-Up for Land Change Projection}

\subsubsection{Deriving Markovian Transition Areas and Conditional Probability}

LULC change could be regarded as a stochastic process, with the different categories as the states of the chain (Weng, 2002). Land-cover in the wooded savanna is highly heterogeneous, and the land-use system is complex; thus LULC change tends to be compatible with first order Markovian dependency. The CA-Markov model exhibits spatial explicitness, allows the use of multiple categories, and can simulate the transition from any category to any other category (Eastman, 2009). It acquires predictive power by combining Markov conditional probabilities and transition areas for each category with suitability maps for each category. CA-Markov deals with complications associated with competition in land change among different pixels by implementing a multiple objective land allocation (MOLA) framework. The spatial explicitness property enables the model to predict both the quantity and location of each category using a suitability map for each transition that it extrapolates. At every time step, it determines the number of pixels that must undergo each transition, then selects the pixels according the largest suitability for the particular transition (Pontius \& Malanson, 2005; Eastman, 2009).

CA-Markov accepts land-cover data from two time points (before and present) as inputs and generates outputs that include transition area files, a transition probability matrix, and a set of conditional probability maps, one for each land-cover category. The cellular automata (CA) component of the model guides the transition probabilities of one pixel to be a function of both the previous state and the state of the local neighborhood, i.e., neighboring pixels. It also helps to filter the suitability of land away from existing areas of that category during iteration and thus provides the model with some explanatory power. The net result is that land-cover changes develop as growth processes in areas of high suitability proximate to existing areas (Hall, Tian, Qi, Pontius, \& Cornell, 1995; Pontius \& Schneider, 2001; Pontius \& Malanson, 2005; Eastman, 2009). Image-derived land cover maps for 1986 and 2006 were used as inputs. During initialization, transition area files, conditional probability matrices (Table 1), and conditional probability maps for each land cover category were generated. 
Table 1. Markov conditional probability matrix between categories (2006 to 2016)

Probability of change to:

\begin{tabular}{cccccccccccccc}
\hline Given & URB & WDL & FOR & SHG & WET & CUV & FAF & FLA & WAT & BAS & ALV & BUS & CLD \\
\hline URB & 0.6453 & 0 & 0 & 0.0462 & 0.0334 & 0.111 & 0.1081 & 0.0298 & 0.0007 & 0.0171 & 0 & 0.003 & 0.006 \\
WDL & 0.0024 & 0.483 & 0.1085 & 0.2516 & 0.0113 & 0.0543 & 0.0319 & 0.0159 & 0.0004 & 0.0063 & 0.0004 & 0.0048 & 0.029 \\
FOR & 0 & 0.291 & 0.6046 & 0.0762 & 0 & 0 & 0.0099 & 0.006 & 0.0023 & 0.0023 & 0 & 0 & 0.008 \\
SHG & 0.0136 & 0.066 & 0.0991 & 0.162 & 0.0362 & 0.1744 & 0.2875 & 0.1163 & 0.0035 & 0.0321 & 0.0005 & 0 & 0.009 \\
WET & 0.0003 & 0.365 & 0.007 & 0 & 0.146 & 0.0049 & 0.2431 & 0.2221 & 0.0112 & 0 & 0.0005 & 0 & 0 \\
CUV & 0.0325 & 0.092 & 0 & 0.1514 & 0.0573 & 0.2709 & 0.297 & 0.0551 & 0 & 0.0311 & 0.0004 & 0.0026 & 0.01 \\
FAF & 0.0026 & 0.424 & 0.0993 & 0.0407 & 0.051 & 0.0547 & 0.2644 & 0.0554 & 0 & 0.0082 & 0 & 0 & 0 \\
FLA & 0.0054 & 0.197 & 0 & 0.1074 & 0.1489 & 0.0808 & 0.3616 & 0.0886 & 0.001 & 0.0091 & 0 & 0 & 0 \\
WAT & 0.0004 & 0 & 0 & 0.0249 & 0.0758 & 0 & 0 & 0.0082 & 0.8796 & 0.0087 & 0 & 0 & 0.003 \\
BAS & 0.0286 & 0.035 & 0.0796 & 0.1496 & 0.03 & 0.2169 & 0.2213 & 0.1551 & 0.0032 & 0.0604 & 0.0024 & 0.0002 & 0.017 \\
ALV & 0.0464 & 0 & 0 & 0.279 & 0.3063 & 0.0321 & 0 & 0.0993 & 0.2146 & 0 & 0.0222 & 0 & 0 \\
BUS & 0.0071 & 0.122 & 0.3421 & 0.1343 & 0.0215 & 0.1173 & 0.1113 & 0.1075 & 0.007 & 0.0237 & 0.0014 & 0 & 0.005 \\
CLD & 0.0597 & 0.235 & 0 & 0.3078 & 0.0327 & 0.1567 & 0 & 0.0767 & 0.0012 & 0.0039 & 0 & 0.0368 & 0.09 \\
\hline URB-urban; & WDL-woodland; & FOR-forest; & SHG-shrub/grassland; & WET-wetland; & CUV-cultivation;
\end{tabular}

URB-urban; WDL-woodland; FOR-forest; SHG-shrub/grassland; WET-wetland; CUV-cultivation; FAF-farmland/fallow; FLA-floodplain agric, WAT-water; BAS-bare surface; ALV-alluvial; BUS-burnt surface; CLD-cloud.

\subsubsection{Preparation of Suitability Maps}

The process of constructing the suitability maps involves the conversion, transformation and integration of several raster and vector data layers. The suitability maps were generated using the multi-criteria evaluation (MCE) module of Idrisi ${ }^{\circledR}$ Taiga. These suitability maps basically represent the integration of the driver maps. Each data layer was standardized and converted into the integer format accepted by the MCE module. The driver maps that defined the criteria in the MCE are divided into factors and constraints. Factors are generally continuous variables (including slope, aspect, elevation, rainfall, temperature) and indicate the relative suitability of certain areas. The total weight point for all of the factors must equal unity. Constraints are Boolean (0 or 1) and include criteria such as distance to water bodies, soil potential for agriculture and protected areas. They serve to exclude certain areas from consideration. The higher the factor weights, the greater their influence on the final suitability maps. Only 8 of the initial 13 defined criteria (see Table 2) were used to generate the final suitability maps for the 13 LULC categories (examples for forest and shrub/grassland in Figures $3 a$ and $b$ ); the others were eliminated for collinearity. Two sets of suitability maps were prepared - for the present day climate scenario and the future climate scenario (see Figures $3 a \& b$ ). 
Table 2. Criteria for generating suitability maps in MCE

\begin{tabular}{|c|c|c|c|}
\hline Code & LULC Class & Factors and score & Constraints \\
\hline 1 & Urban & Elevation $(0.6)+$ slope $(0.4)$ & $\begin{array}{l}\text { distance to water body and } \\
\text { protected areas }\end{array}$ \\
\hline 2 & Woodland & $\begin{array}{l}\text { Mean annual rainfall }(0.6)+\text { mean maximum temperature } \\
(0.4)\end{array}$ & soil potential for agric \\
\hline 3 & Forest & $\begin{array}{l}\text { Mean annual rainfall }(0.4)+\text { mean maximum temperature } \\
\qquad(0.4)+\text { Elevation }(0.2)\end{array}$ & soil potential for agric \\
\hline 4 & Shrub/grassland & Aspect $(0.6)+$ mean maximum temperature $(0.4)$ & \\
\hline 5 & Wetland & Aspect $(0.4)+$ Mean annual rainfall $(0.6)$ & mean maximum temperature \\
\hline 6 & $\begin{array}{l}\text { Cultivation } \\
\text { /commercial agric }\end{array}$ & $\begin{array}{l}\text { Mean annual rainfall }(0.6)+\text { mean maximum temperature } \\
(0.4)\end{array}$ & soil potential for agric \\
\hline 7 & $\begin{array}{l}\text { Farmland/fallow/gr } \\
\text { azing area }\end{array}$ & $\begin{array}{l}\text { Mean annual rainfall }(0.6)+\text { mean maximum temperature } \\
(0.4)\end{array}$ & distance to water body \\
\hline 8 & Floodplain agric & Mean annual rainfall (1) & soil potential for agric \\
\hline 9 & Water & Mean annual rainfall (1) & mean maximum temperature \\
\hline 10 & Bare surface & $\begin{array}{l}\text { mean maximum temperature }(0.4)+\text { Elevation }(0.4)+\text { aspect } \\
(0.2)\end{array}$ & distance to water body \\
\hline 11 & Alluvial & Mean annual rainfall (1) & slope \\
\hline 12 & Burnt surface & Mean maximum temperature (1) & distance to water body \\
\hline 13 & Cloud /shadow & Mean annual rainfall (1) & \\
\hline
\end{tabular}
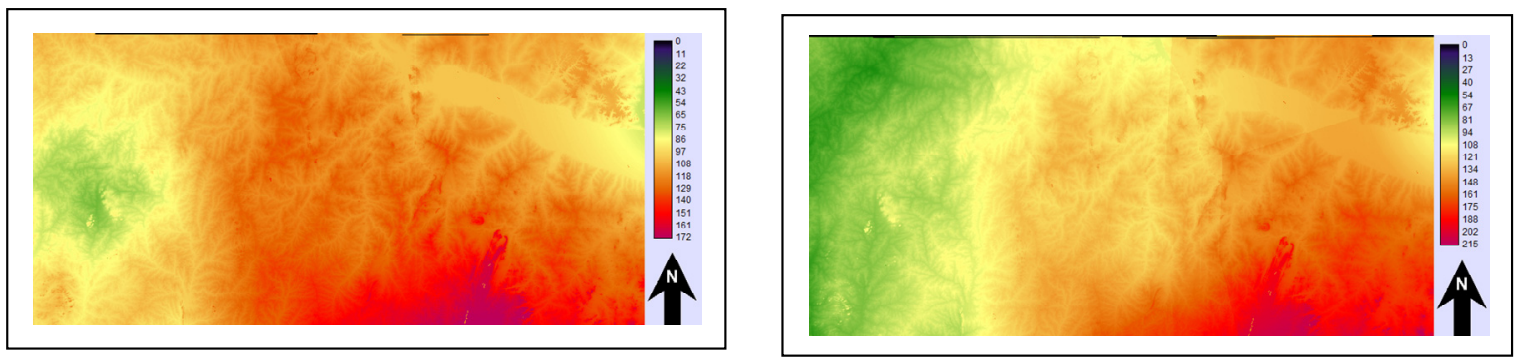

Figure 3a. Suitability map for Class 3 (forest) under present day (Left) and future (2046-2065- Right) climate scenarios
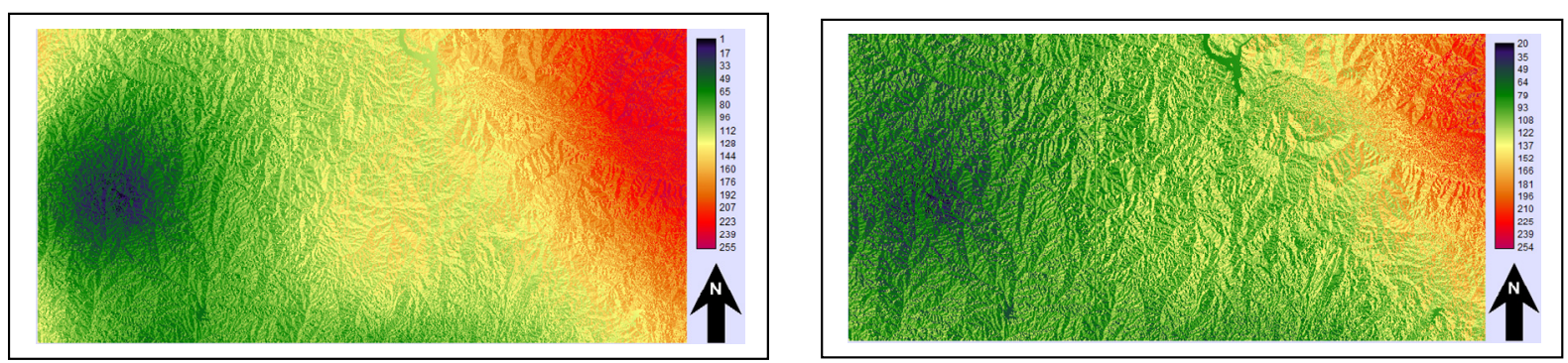

Figure 3b. Suitability map for Class 4 (shrub/grassland) under present day (Left) and future (2045-2065-Right) climate scenarios

\subsubsection{Model Simulation}

Each model run uses the suitability map collection with the basis land-cover map (image-derived 2006 map), Markov transition areas file, and conditional probability matrices to simulate future land-cover, placing simulated change in cells that have the largest suitability values. If the suitability map was perfect, the order of the suitability values would match the order in which humans change the landscape, with the largest suitability values being changed first (Hall et al., 1995; Pontius \& Schneider, 2001). The model was run for 4 scenarios: 2006 to 2016, with 10 iterations (1-year time-step); 2006 to 2026, with 20 iterations (1-year time-step); 2006 to 
2036, with 15 iterations (2-year time-step) and 2006 to 2046, with 20 iterations (2-year time-step). The choice of number of iterations and time step was based on the need to reduce the simulation time which is about 24 hours for 20 iterations on a 500 GB HD, Intel Core 2 Duo $2.1 \mathrm{GHz}, 4$ GB RAM Laptop computer that was used. For all model runs, the standard $5 \times 5$ contiguity filter was used.

Within each time step, each land-cover class is considered in turn as a host category. All other land-cover classes act as claimant classes and compete for land (only within the host class) using the MOLA procedure. The area requirements for each claimant class within each host are equal to the total established by the transition area file divided by the number of iterations. Whereas the demand for land by different land-cover categories determines the overall competitive capacity of each land-cover type, the location's suitability is a major determinant of the competitive capacity of each land-cover type at a specific location (Verburg, Eickhout, \& Meij, 2007). We carried out two sets of simulations i.e. under both present day and future climate scenarios using the present and future rainfall and maximum temperature as a driver input into the MCE suitability images. This means that the climate drivers were varied, while others drivers were assumed to be constant.

\subsection{Model Validation}

The validation step attempts to simulate the map of a known period and compare it with the Landsat image-derived map of the same period. To validate the simulated results, we used the 1986 and 2000 land-cover maps for initialization and then used the land-cover map of 2000 as the basis land-cover and perform an additional run (2000 to 2006) with 12 iterations (6-month time-step). The relative operating characteristics (ROC) for the model was also computed. How well the category of interest is concentrated at locations of relatively high suitability for that category is determined by the ROC. For the CA-Markov model, the ROC statistic measures the similarity between the simulated change and the real change and works for exactly two land-cover categories (Pontius \& Schneider, 2001). ROC examines the agreement between a Boolean map of one category and a suitability map for that category. The computed ROC was above 0.70 for all of the 13 land-cover categories. An ROC of 0.50 represents an agreement due to chance, 0.70 represents a good agreement between the simulated maps of the different categories and their suitability maps.

\section{Results}

\subsection{LULC Change Under the Present Day Climate Scenario}

The present climate for the wooded savanna is characterized by a maximum temperature increase on the order of approximately $0.06{ }^{\circ} \mathrm{C} /$ month/decade, with the years 1998 to 2006 (except 1999) exhibiting continuously increasing maximum temperature anomalies. Rainfall increased marginally by approximately 0.6 $\mathrm{mm} / \mathrm{month} /$ decade. Table 3 shows a comparison of the percent coverage of each land-cover category in 1986 and 2006 and their simulated coverage for 2016 to 2046 under the present climate scenario.

Table 3. Percent coverage of current (1986 and 2006) and simulated (2016 to 2046) LULC under present day climate scenario

\begin{tabular}{clcccccc}
\hline SN & LULC Class & Mapped & Mapped & Projected & Projected & Projected & Projected \\
& 1986 & 2006 & 2016 & 2026 & 2036 & 2046 \\
\hline 1 & Urban & 0.80 & 1.45 & 2.82 & 3.93 & 4.82 & 5.36 \\
2 & Woodland & 19.70 & 32.11 & 20.68 & 26.93 & 23.09 & 22.62 \\
3 & Forest & 13.48 & 15.63 & 18.36 & 15.12 & 15.06 & 14.68 \\
4 & Shrub/grassland & 3.27 & 12.95 & 21.55 & 26.74 & 27.21 & 27.20 \\
5 & Wetland & 5.27 & 4.14 & 2.55 & 1.64 & 1.89 & 1.50 \\
6 & cultivation/commercial agric & 11.07 & 8.16 & 12.34 & 9.84 & 10.17 & 10.44 \\
7 & Farmland /fallow/grazing area & 32.61 & 16.79 & 8.21 & 4.80 & 6.89 & 6.79 \\
8 & Floodplain agric & 4.16 & 5.63 & 6.81 & 4.38 & 3.51 & 3.61 \\
9 & Water & 0.55 & 0.70 & 1.23 & 1.67 & 2.07 & 2.45 \\
10 & Bare surface & 2.61 & 1.23 & 1.01 & 1.33 & 1.53 & 1.59 \\
11 & Alluvial & 0.04 & 0.03 & 0.02 & 0.01 & 0.02 & 0.01 \\
12 & Burnt surface/fire scar & 5.84 & 0.15 & 0.67 & 0.49 & 0.46 & 0.52 \\
13 & Cloud/shadow & 0.61 & 1.04 & 3.74 & 3.13 & 3.27 & 3.22 \\
\hline
\end{tabular}


A comparison of the 1986 and 2006 LULC maps suggests significant recovery. Forests and woodlands which are the two major canopy ecosystems increased in extent in 2006 compared to 1986. Simulated future land-cover projections under the present climate scenario suggest that built-up areas (human settlements) would likely experience a consistent increase from $1.5 \%$ in 2006 to $5.4 \%$ in 2046. Area under cultivation is projected to peak at approximately $12 \%$ in 2016 (compared to 8\% in 2006) and then stabilizes around 10\% from 2026 to 2046. Unutilized farmland and fallow land is projected to continue to decline as the area under cultivation increases, and will retain only $60 \%$ of its 2006 coverage by 2046 . The major canopy ecosystems are very sensitive to changes in climatic parameters, especially rainfall. The overall percent coverage of forest is projected to increase from $15.6 \%$ in 2006 to $18 \%$ in 2016 , and then remain stable at around $15 \%$ from 2025 to 2046 . The coverage of woodlands is projected to remain above $20 \%$ from 2006 to 2046. Some transition from woodlands and fallow lands into forest is also projected. The strongest gain with respect to transitions from one land-cover category to another is projected for the shrub/grassland category. Shrub/grassland is expected to increase by approximately $110 \%$ of its coverage in 2006 with contributions mainly from woodlands and abandoned farm and fallow lands. Total area covered by wetland is projected to consistently decline from approximately $1,650 \mathrm{~km}^{2}$ in 2006 to less than $600 \mathrm{~km}^{2}$ in 2046 . The area covered by water is also projected to consistently increase, which suggests more water impoundments into the future. Floodplain agriculture is expected to peak at approximately $7 \%$ of the total area in 2016 and then stabilize at approximately 4\% from 2026 to 2046.

Figure 4a presents the spatial pattern of land-cover for the mapped years 1986 and 2006 and Figure 4b shows the spatial pattern for the simulated maps of years 2036 and 2046.

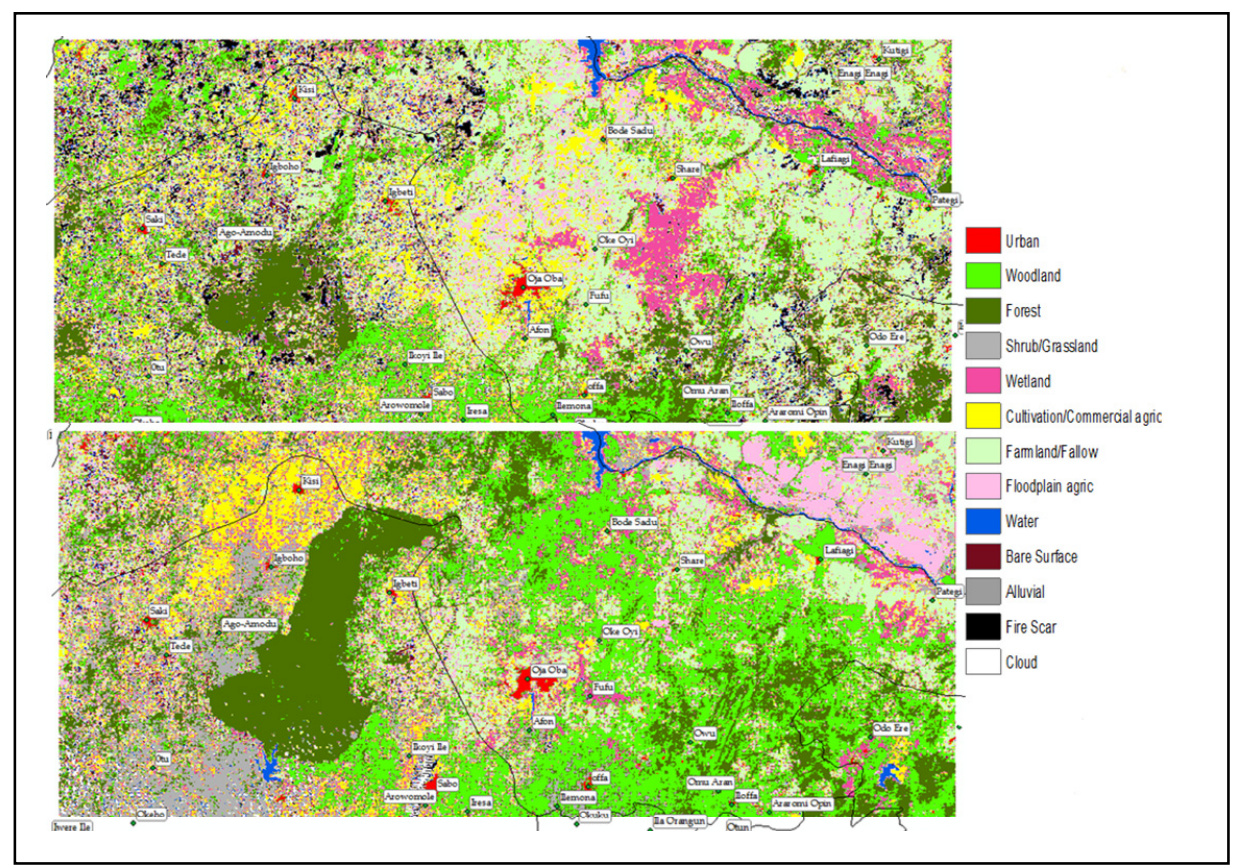

Figure 4a. Landsat image-derived LULC for 1986 (upper) and 2006 (lower) 


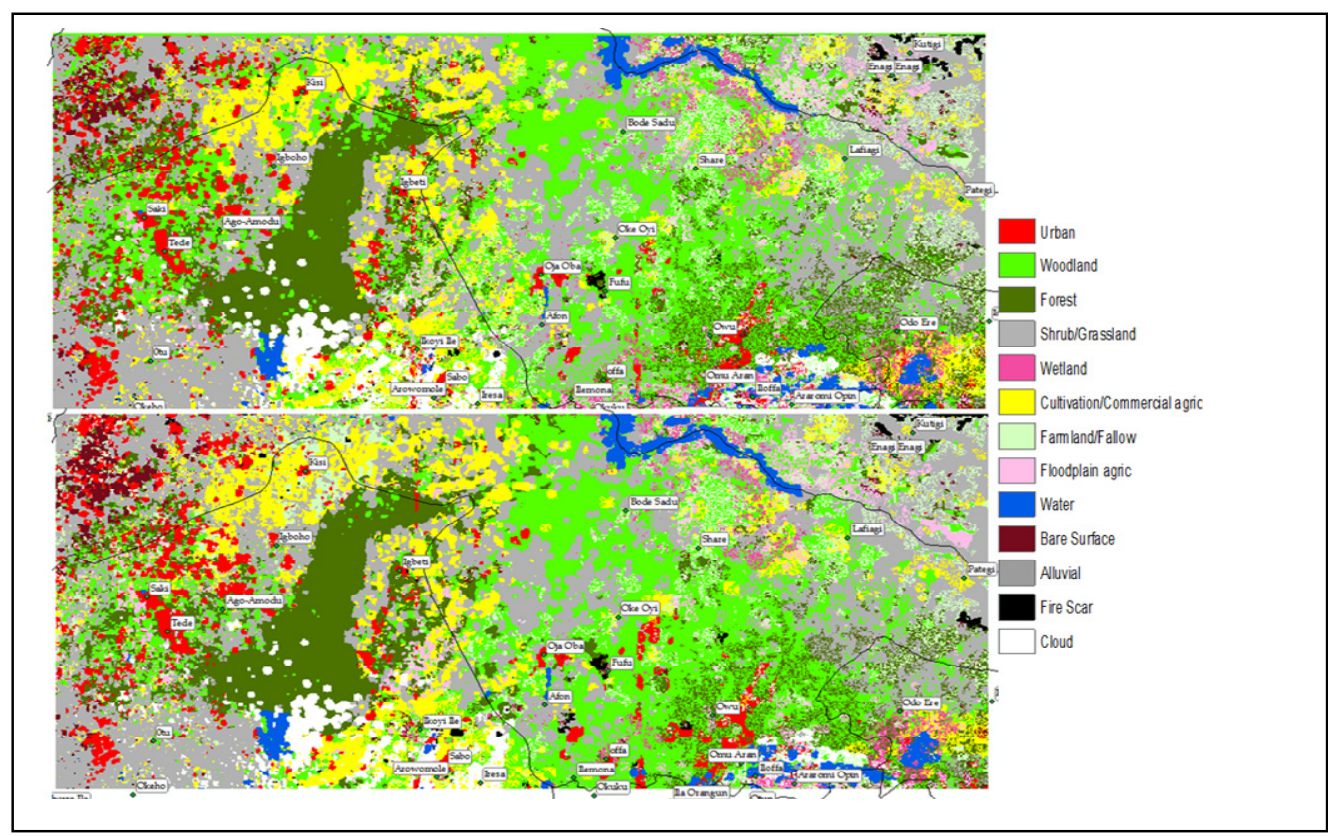

Figure 4b. Simulated LULC maps under the present day climate scenario for 2036 (upper) and 2046 (lower)

The simulated LULC changes for 2006 to 2046 show an increase in the coverage of shrub/grassland in some pocket areas around the northeast, central and southwest axes. These are farmlands and fallow lands transitioning into shrub/grasslands. The protected forest complex is projected to remain relatively undisturbed, while mosaics of forest and woodland will likely dominate the southeast corridor. From 2006 to 2046, the built-up area is projected to continue to increase. Significantly, the largest growth in built-up lands is projected for areas around the northwest to southwest corridor. In response to increase in built-up area, additional cultivated areas are also projected to emerge around this corridor, which reinforces the strong connection between agriculture and settlement in rural land use systems.

\subsection{Projected LULC Under the Future Climate Scenario}

The future climate scenarios suggest a significant decline in rainfall (by approximately $4 \mathrm{~mm} / \mathrm{month} / \mathrm{decade}$ ) and an increase $\left(0.02{ }^{\circ} \mathrm{C} /\right.$ month/decade) in the mean monthly maximum temperature (Fasona, Tadross, Abiodun, \& Omojola, 2013). Table 4 presents a comparison of the simulated coverage (in percent) of the LULC categories, and Figure 5 shows the spatial pattern of the simulated LULC maps under the future climate scenario.

Table 4. Percent coverage of simulated LULC maps for 2006-2046 in future climate scenario

\begin{tabular}{llcccc}
\hline SN & LULC Class & $\begin{array}{c}\text { Projected } \\
\mathbf{2 0 1 6}\end{array}$ & $\begin{array}{c}\text { Projected } \\
\mathbf{2 0 2 6}\end{array}$ & $\begin{array}{c}\text { Projected } \\
\mathbf{2 0 3 6}\end{array}$ & $\begin{array}{c}\text { Projected } \\
\mathbf{2 0 4 6}\end{array}$ \\
\hline 1 & Urban & 2.84 & 3.93 & 4.85 & 5.36 \\
2 & Woodland & 15.26 & 16.57 & 16.74 & 19.41 \\
3 & Forest & 19.91 & 16.66 & 15.32 & 14.66 \\
4 & Shrub/grassland & 19.33 & 26.30 & 26.85 & 27.16 \\
5 & Wetland & 2.71 & 1.61 & 2.12 & 1.67 \\
6 & Cultivation /commercial agric & 7.81 & 8.54 & 9.82 & 10.16 \\
7 & Farmland /fallow/grazing area & 21.49 & 16.57 & 13.20 & 10.20 \\
8 & Floodplain agric & 3.86 & 3.24 & 3.69 & 3.60 \\
9 & Water & 1.21 & 1.64 & 2.07 & 2.42 \\
10 & Bare surface & 1.07 & 1.32 & 1.54 & 1.59 \\
\hline
\end{tabular}




\begin{tabular}{llllll}
\hline 11 & Alluvial & 0.02 & 0.01 & 0.01 & 0.01 \\
12 & Burnt surface & 0.74 & 0.49 & 0.53 & 0.52 \\
13 & Cloud /shadow & 3.74 & 3.13 & 3.27 & 3.22 \\
\hline
\end{tabular}

Forest is projected to increase from $15.6 \%$ in 2006 to approximately $20 \%$ in 2016 , then decline to about $17 \%$ in 2026 and stabilizes at approximately $15 \%$ from 2036 to 2046 which is higher than $14.68 \%$ under future climate scenarios. Additionally, the area covered by woodland is expected to progressively increase from $15 \%$ in 2016 to $19 \%$ by 2046 which is lower than $22.62 \%$ under the present day climate scenario.

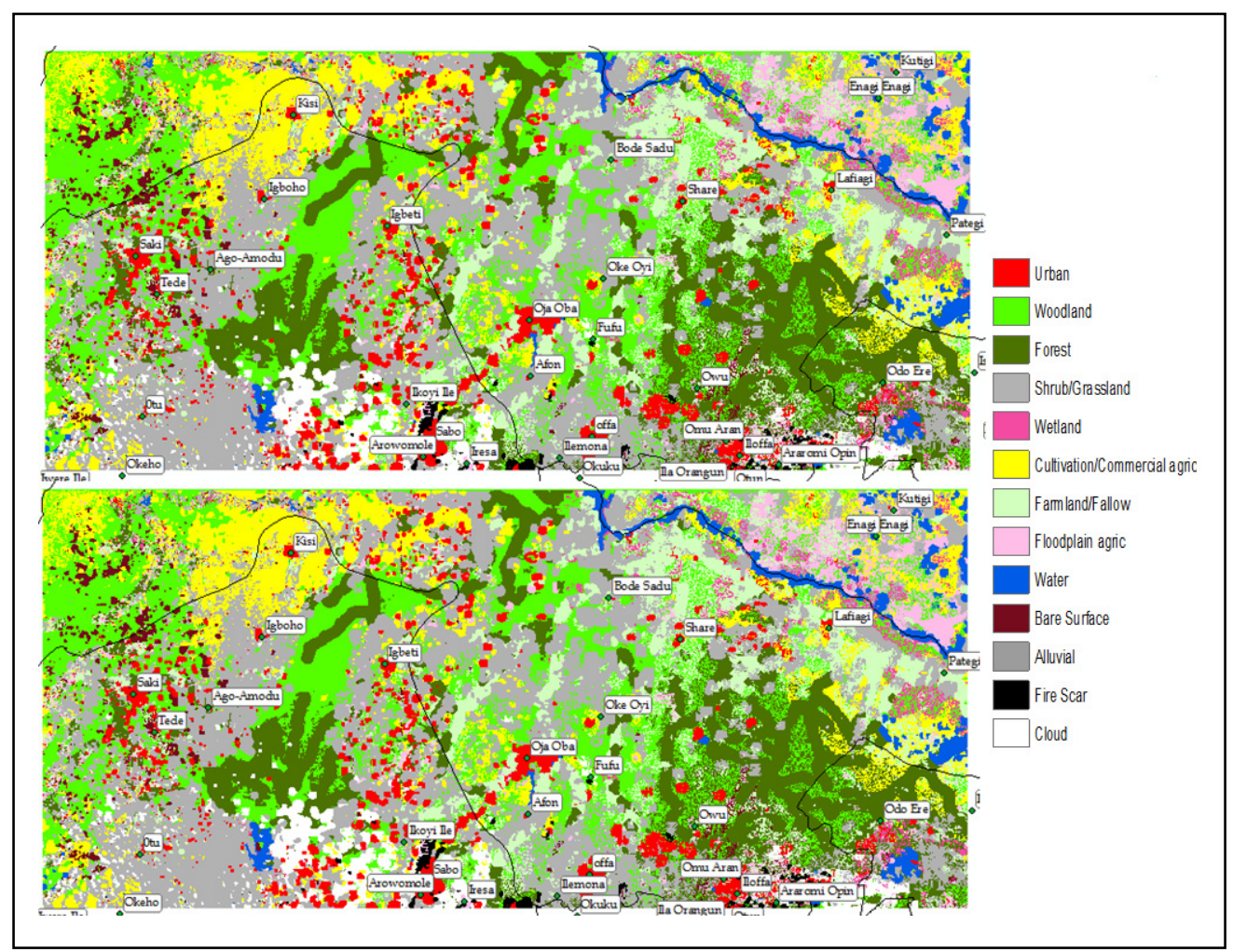

Figure 5. Projected LULC under future climate scenarios in 2036 (upper) and 2046 (lower)

Moreover, the major difference between the simulated LULC patterns under the present and future climate scenarios is the spatial pattern of the LULC categories. Under the future climate scenario, the forests would likely become more disturbed, with galleria forest becoming the most significant forest type. Shrub/grassland will also become much more widespread. Galleria forest and widespread shrub/grassland generally typify the drier parts (Sudan and Sahel) of the Savanna. This suggests that under the future climate scenario, as the wooded savanna will likely become drier, the vegetation pattern may change dramatically. The spatial pattern of built-up lands suggests that more settlements are projected to emerge around the middle region, especially along the Oyo, Ogbomosho, Igbeti and Ilorin axis, compared to the western axis under present day climate.

\subsection{Model Calibration}

With the 1986 and 2000 maps representing the basis land-cover, a map for 2006 was simulated using a 6-month time-step. The areal agreements between the real and simulated maps and their spatial patterns were compared. The agreement in terms of quantity was good and was almost equal for most of the categories. The essential features of the area, including the large track of protected area, cultivated lands around the northwest, water impoundments, river networks, shrub/grasslands around the south-west, the floodplain of the Niger River, and the mosaic of forests and woodlands around the southeast are well captured (Figure 6). 


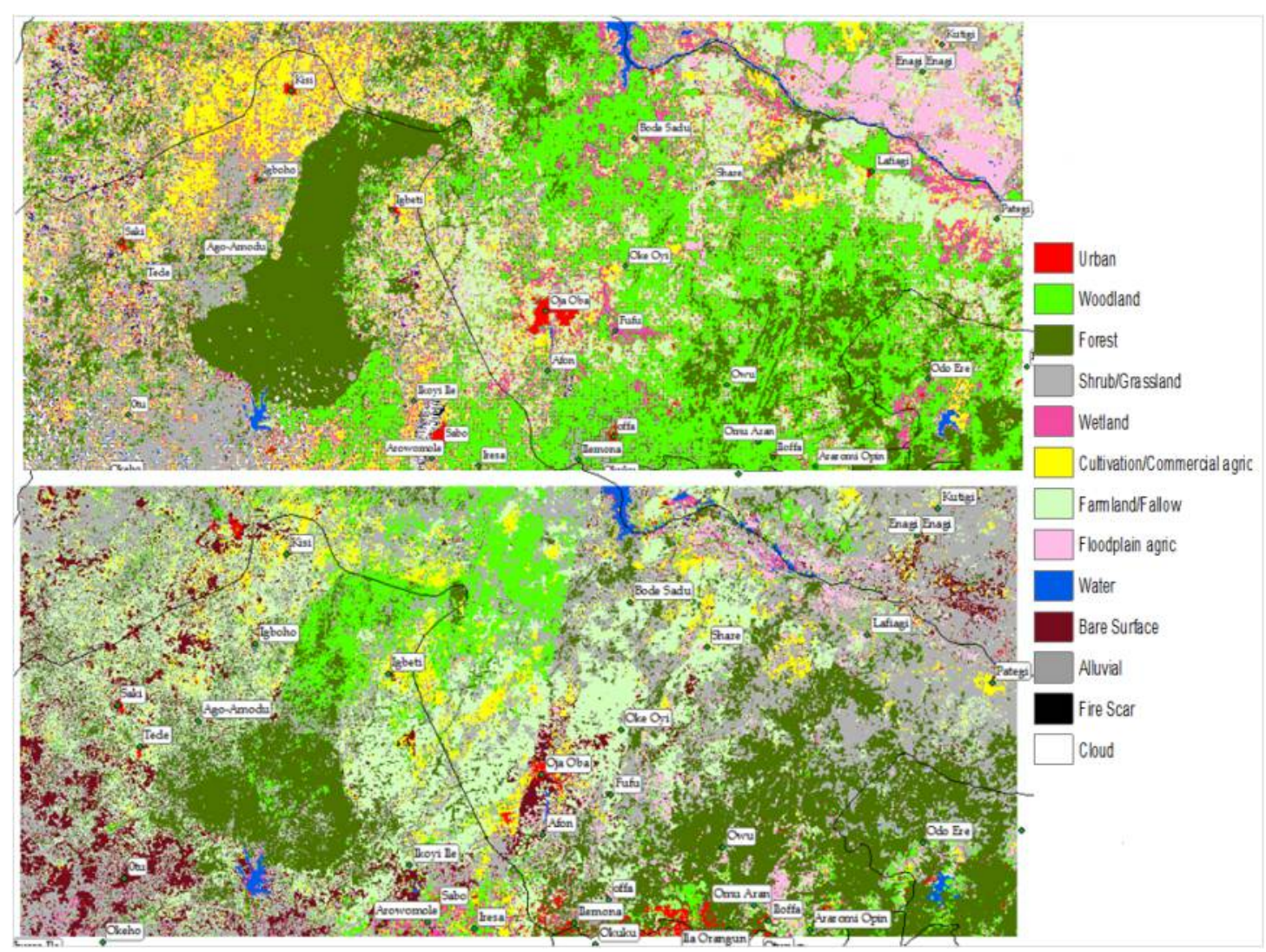

Figure 6. Coverage of LULC categories for real (upper) and simulated (lower) maps for 2006

The greatest uncertainty is the confusion between the woodland areas on the real map and the shrub/grassland areas on the simulated map. The lack of field confirmation and accuracy assessments of the image-derived land-cover maps may have contributed to this poor agreement. Another possible explanation is the lack of an intermediate year map (for the 1990s). Hence, the model might have difficulty capturing the abrupt transition from the drought years of the 1980 s to the relatively wet years of the 2000s. The simulation results are projections based on the assumed climatic scenarios and represent a quantified visualization of qualitative scenario descriptions. Uncertainty is a common element in scenario building (Tol, 1998; Smith \& Hulme, 1998; Quetier, Lavorel, Daigney, \& de Chazal, 2009). Notwithstanding, the simulated maps are useful as guide for decisions related to climate change and management of land resources. The scenarios could also support awareness, discussions and decisions relating to climate change adaptation and local mitigation actions.

\section{Discussion}

The wooded savanna is characterized by land-use complexity and land-cover heterogeneity with rapid land transformation and strong resilience. A piece of land can serve different uses at different times depending on human decisions, season of the year, and the seasonal pattern of rainfall and temperature. Abandoned fields and fallows used for animal grazing in dry season may become blossom cultivated fields in the wet season. Agriculture provides the main source of livelihood. Footprints of discontinuous peasant small-holder, rain-fed agriculture generally dominates the landscape. This is consistent with the findings of Tiwari et al. (2010) with respect to land-use dynamics among peasant farmers in southern India.

The significant recovery in the ecosystem recorded in 2006 compared to 1986 is consistent with the findings of Nicholson (2000); Stow et al. (2004) and Lauwaet, Van Lipzig and De Ridder (2009) on the recent land-cover recovery in the Sahel which suggests a progressive increase in rainfall from the late 1980s to the present and a concomitant increase in the vegetal cover. However, the transition from woodlands and fallow area to the shrub/grassland category was rapid, which suggests significant human disturbance. The spatial pattern of built-up lands also suggests that more settlements are projected to emerge around the middle region, especially along the Oyo, Ogbomosho, Igbeti and Ilorin axis, compared to the western axis, under present day climate. This is also consistent with the expected decline in the spatial influence of the climate-orographic complex that 
controls the local climate that may weaken the local system on the western axis and reduce the water footprint in the future (Fasona, Tadross, Abiodun, \& Omojola, 2011). The possibility of the canopy ecosystems becoming more disturbed with more widespread shrub/grassland and the galleria forest becoming the most significant forest in future climate scenario is also consistent with substantial biodiversity change and vegetal degradation projected across Africa regions (Alo \& Wang, 2008; Muller, 2009) and the possibility of tropical forests being replaced by deciduous forests under warmer climate (Delire et al., 2008; Wright, 2010).

The large footprint of small-holder subsistence agriculture in the western axis suggests that the lands are highly productive. The area which is locally referred to as the 'Oke-Ogun' area (i.e. upper Ogun River) is generally known as the 'food basket of western Nigeria.' Its arable land supports the production of varieties of root, tuber and cereal crops. The wetter and cooler climate conditions in this axis support the natural resource systems compared to other areas. As a result the density of rural settlements is high and resource conflict is common. The future LULC simulations under the present day climate suggest that the western axis will experience the fastest growth of settlements. This suggests that rural-to-rural migration will likely increase as an adaptive response to climate change. There is a possibility that many subsistence farmers will abandon their unproductive marginal lands in other areas in search of productive lands around the western axis. This phenomenon is generally common among small-holder farmers in western Nigeria due to declining land productivity caused by adverse climate conditions. This may also present a potential for increased conflicts over natural resources. In the future climate scenario, the local climate condition that presently supports favourable agriculture in the western axis is projected to weaken and the area will get drier (Fasona et al., 2013). This has the potential to cause a dislocation of the livelihood systems with a decline in areas under cultivation. This may lead to people migrating from this axis to the middle axis where better local climate conditions are projected to prevail.

The central area consists of large tracts of protected forest complex, open woodlands and fallow lands. Under the present climate scenario, the protected forest complex is projected to remain relatively intact. However, under future climate scenario, some serious natural disturbance is expected possibly due to declining rainfall. This may also be connected to the warmer conditions and declining rainfall expected in the western axis. More settlements and cultivated lands are also projected for the central area especially around the edges of the forest complex in the future climate scenario. This means a possible shift in activities from the western to the central axis under future climate.

The eastern axis presently consists of mosaics of forest and woodland located around elevated areas and riparian freshwater forest and wetland in the Niger River floodplain. This axis has the greatest potential for ecosystem preservation and albedo enhancement as a climate mitigation option. However, the forests and woodlands are projected to become more disturbed in future warmer climate scenario with shrub/grassland expected to emerge across large areas. Floodplain agriculture is also likely to increase as an adaptation to climate change. The emergence of galleria forest as the dominant forest type under the future climate scenario suggests that measures to protect current forests and woodlands need to be taking more serious. Changes in LULC that reduce canopy ecosystems will correspondingly increase surface albedo, reduce leaf area index (LAI) and infiltration, and increase surface run-off. The connections between climate and ecosystems maintain the flow of surface drainage which is important for domestic and agricultural water use. Changes in the LAI can significantly affect regional and local climate conditions, especially with respect to rainfall, by affecting the amount of moisture available for evaporation at the surface (MacKellar et al., 2009). This is particularly relevant in the wooded savanna where a significant fraction of the total annual rainfall is due to mesoscale processes that rely on local eco-geographic factors including the land-cover. Forest and woodland reduction are associated with a reduction in LAI and by implication a reduction in the capacity of the ecosystems to sequester carbon. An increase in the area covered by shrub/grasses also increases 'savannisation' (Nobre \& Borma, 2009). Changes in landscape-pattern resulting from fragmented land-cover affect natural population viability. Although the simulated coverage of forest is expected to be slightly higher under future climate scenario than the present climate, large contiguous forests may give way to more fragmented patches. This has the possibility to weaken the local climate system. The study area is an important headwater; and since land-cover is critical for catchment fluxes, catchment protection also becomes a critical issue to be considered.

\section{Conclusions}

The key issues addressed in this paper are: that climate change has the potential to influence the patterns of land-cover across space and time in complex and heterogeneous landscapes; and land change models developed using remote sensing and GIS have the potential to complement climate models to improve our understanding of climate and land-cover feedbacks especially at local and sub-national scales. Image-derived land-cover maps for 1986 and 2006 were the basis land-cover, and change suitabilities were generated by integrating change drivers 
developed from eco-geographic factors including present day and future climate data. Future land-cover maps under the present and future climate scenarios were simulated using Idrisi®'s CA-Markov model.

Under both present day and future climate scenarios, built-up areas are projected to experience a consistent increase but the pattern of distribution is expected to be different in the two scenarios. Rural to rural migration in search of favourable agricultural land will likely be significant under both present day and future climate scenarios. This presents a potential for increased resource-induced conflicts. Significant change in the landscape pattern is expected with galleria becoming the dominant forest type in the future climate scenario. This suggests that there will be a dramatic change in the vegetation patterns as the wooded savanna becomes drier.

We recognized that a host of other underlying factors including tenure regimes, technological change, demographic, social and economic changes, globalization of markets, agricultural policy changes, and political decisions which are out of immediate control can also play significant roles in present and future land-cover changes. This study has, however, demonstrated that land change models have the potential to complement climate models to provide better understanding of climate and land-cover feedbacks at local levels.

\section{Acknowledgments}

This research was carried out under the African Climate Change Fellowship Programme (ACCFP) postdoctoral fellowship at the University of Cape Town awarded to MF. The ACCFP is supported by a grant from the Climate Change Adaptation in Africa (CCAA) jointly funded by IDRC and DFID. The International START Secretariat is the implementing agency in collaboration with the Institute of Resource Assessment (IRA) of the University of Dar es Salaam and the African Academy of Sciences (AAS).

The authors are grateful to the editor and the 3 anonymous reviewers for their useful comments.

\section{References}

Abiodun, B. J., Pal, J. S., Afiesimama, E. A., Gutowski, W. J., \& Adedoyin, A. (2008). Simulation of West African monsoon using RegCM3 Part II: impacts of deforestation and desertification. Theoretical and Applied Climatology, 93, 245-261. http://dx.doi.org/10.1007/s00704-007-0333-1

Afiesimama, E. A., Pal, J. S., Abiodun, B. J., Gutowski Jr, W. J., \& Adedoyin, A. (2006). Simulation of West African monsoon using the RegCM3.Part I: Model validation and interannual variability. Theoretical and Applied Climatology, 86, 23-37. http://dx.doi.org/10.1007/s00704-005-0202-8

Alo, C. A., \& Wang, G. (2008). Potential future changes of the terrestrial ecosystem based on climate projections by eight general circulation models. Journal of Geophysical Research, 113(G1), G01004. http://dx.doi.org/10.1029/2007JG000528

Anderson, J. R. (1976). A land use and land cover classification system for use with remote sensor data (Vol. 964). US Government Printing Office.

Bucini, G., \& Lambin, E. F. (2002). Fire impacts on vegetation in Central Africa: a remote-sensing-based statistical analysis. Applied Geography, 22, 27-48. http://dx.doi.org/10.1016/S0143-6228(01)00020-0

Cook, K. H., \& Vizy, E. K. (2006). Coupled Model simulation of the West African Monsoon Systems: Twentieth-and Twenty-First Century Simulations. Journal of Climate, 19, 3681-3703. http://dx.doi.org/10.1175/JCLI3814.1

Delire, C., Ngomanda, A., \& Jolly, D. (2008). Possible impacts of 21st Century Climate on Vegetation in Central and West Africa. Global and Planetary Change, 64, 3-15. http://dx.doi.org/10.1016/j.gloplacha.2008.01.008

Eastman, J. R. (2009). Idrisi Taiga Guide to Image Processing. USA: Clark Labs, Worcester, MA.

Fasona, M., Omojola, A., Adeaga, O., \& Dabi, D. (2007). Aspects of Climate Change and Resource Conflicts in the Nigeria Savanna. IPCC/TGICA Expert Meeting on Integrating Analysis of Regional Climate Change and Response Options, Nadi, Fiji Islands. Retrieved from http://www.ipcc.ch/pdf/supporting-material/tgica_reg-meet-fiji-2007.pdf

Fasona, M., Tadross, M., Abiodun, B., \& Omojola, A. (2011). Local Climate Forcing and Eco-climatic complexes in the Wooded Savanna of Nigeria. Natural Resources, 20, 155-166. http://dx.doi.org/10.4236/nr.2011.23021

Fasona, M., Tadross, M., Abiodun, B., \& Omojola, A. (2013). Some Implications of Terrestrial Ecosystems Response to Climate Change for Adaptation in Nigeria's Wooded Savanna. Environmental Development, 5, 73-95. http://dx.doi.org/10.1016/j.envdev.2012.11.003 
German Advisory Council on Climate Change. (2008). Climate Change as a security risk. U.K: Earthscan.

Hall, C. A. S., Tian, H., Qi, Y., Pontius, G., \& Cornell, J. (1995). Modelling Spatial and Temporal Patterns of Tropical Land Use Change. Terrestrial Ecosystem Interactions with Global Change, 2, 753-757.

Hély, C., Bremond, L., Alleaume., S, Smith, B., Sykes, M. T., \& Guiot, J. (2006). Sensitivity of African biomes to changes in the precipitation regime. Global Ecology and Biogeography, 15, 258-270

Hewitson, B. C., \& Crane, R. G. (2006). Consensus between GCM climate change projections with empirical downscaling: precipitation downscaling over South Africa. International Journal of Climatology, 26, 1315-1337. http://dx.doi.org/10.1002/joc.1314

Hoffman, T., \& Vogel, C. (2008). Climate Change Impacts on African Rangelands. Rangelands, 30(3), 12-17.

Hoffmann, W. A., \& Jackson, R. B. (2000). Vegetation-Climate Feedbacks in the Conversion of Tropical Savanna to Grassland. Journal of Climate, 13, 1593-1602. http://dx.doi.org/10.2111/1551-501X(2008)30[12:CCIOAR]2.0.CO;2

Kottek, M., Grieser, J., Beck, C., Rudolf, B., \& Ru, F. (2006). World map of the Köppen-Geiger climate classification updated. $\quad$ Meteorologische 259-263. http://dx.doi.org/10.1127/0941-2948/2006/0130

Lauwaet, D., van Lipzig, N. P. M., \& De Ridder, E. K. (2009). The effect of vegetation changes on precipitation and Mesoscale Convective Systems in the Sahel. Dynamic Climatology, 33, 521-534. http://dx.doi.org/10.1007/s00382-009-0539-2

Leary, N., Kulkarni, J., \& Seipt, C. (2007). Assessment of Impacts and Adaptation to Climate Change. Final Report of the AIACC Project. A Global Environment Facility Enabling Activity in the Climate Change Focal Area Project No. GFL-2328-2724-4330.

Li, X. Y., Ma, Y. J., Xu, H. Y., Wang, J. H., \& Zhang, D. S. (2009). Impact of land use and land cover change on environmental degradation in Lake Qinghai watershed, northeast Qinghai-Tibet Plateau. Land Degradation \& Development, 20(1), 69-83. http://dx.doi.org/10.1002/ldr.885

MacKellar, N. C., Tadross, M. A., \& Hewitson, B. C. (2009). Effects of vegetation map change in MM5 simulations of southern Africa's summer climate. International Journal of Climatology, 29, 885-898. http://dx.doi.org/10.1002/joc. 1754

Nakicenovic, N., Davidson, A., Davis, G., Grübler, A., Kram, T., La Rovere, E., ... Dadi, Z. (2000). Special Report on Emissions Scenarios: A Special Report of Working Group III of the Intergovernmental Panel on Climate Change (p. 599). Cambridge, UK: Cambridge University Press. Retrieved from http://www.grida.no/climate/ipcc/emission/index.htm

Neigh, C. S. R., Tucker, C. J., \& Townshend, J. R. G. (2008). North American vegetation dynamics observed with multi-resolution satellite data. Remote Sensing of Environment, 112, 1749-1772. http://dx.doi.org/10.1016/j.rse.2007.08.018

Nicholson, S. (2000). Land surface processes and Sahel climate. Reviews of Geophysics, 38(1), 117-339. http://dx.doi.org/10.1029/1999RG900014

Nobre, C. A., \& Borma, L. D. (2009). Tipping points for the Amazon forest. Current Opinion in Environmental Sustainability, 1(1), 28-36. http://dx.doi.org/10.1016/j.cosust.2009.07.003

Odekunle, T. O., Balogun, E. E., \& Ogunkoya, O. O. (2005). On the prediction of rainfall onset and retreat dates in Nigeria. Theoretical and Applied Climatology, 81, 101-112. http://dx.doi.org/10.1007/s00704-004-0108-x

Omotosho, J. B., \& Abiodun, J. (2007). A numerical study of moisture build-up and rainfall over West Africa. Meteorological Applications, 14, 209-225. http://dx.doi.org/10.1002/met.11

Pontius Jr, G. R., \& Malanson, J. (2005). Comparison of the structure and accuracy of two land change models, International Journal of Geographical Information Science, 19(2), 243-265. http://dx.doi.org/10.1080/13658810410001713434

Pontius Jr, R. G., \& Schneider, L. C. (2001). Land-cover change model validation by an ROC method for the Ipswich watershed, Massachusetts, USA. Agriculture, Ecosystems and Environment, 85, 239-248. http://dx.doi.org/10.1016/S0167-8809(01)00187-6

Quétier, F., Lavorel, S., Daigney, S., \& de Chazal, J. (2009). Assessing ecological and social uncertainty in the evaluation of land-use impacts on ecosystem services. Journal of Land Use Science, 4(3), 173-199. 
http://dx.doi.org/10.1080/17474230903036667

Smith, J. B., \& Hulme, M. (1998). Climate Change Scenarios. In F. Jan, J. F. Feenstra, I. Burton, J. B. Smith \& R. S. J. Tol (Eds.), Handbook on Methods for Climate Change Impact Assessment and Adaptation Strategies. Version 2.0, UNEP/IVM Handbook.

Solomon, S., Qin, D., Manning, M., Alley, R. B., Berntsen, T., Bindoff, N. L., ... Wratt, D. (2007). Technical Summary. In S. Solomon, D. Quin, M. Manning, Z. Chen, M. Marquis, K. B. Averyt, ... H. L. Miller (Eds.), The Physical Science Basis. Contribution of Working Group I to the Fourth Assessment Report of the Intergovernmental Panel on Climate Change, Climate Change 2007. Cambridge, UK: Cambridge University Press.

Stow, D. A., Hope, A., McGuire, D., Verbyla, D., Gamon, J., Huemmrich, F., ... Myneni, R. (2004). Remote sensing of vegetation and land-cover change in Arctic Tundra Ecosystems. Remote Sensing of Environment, 89(3), 281-308. http://dx.doi.org/10.1016/j.rse.2003.10.018

Taylor, C. M., Lambin, E. F., Stephenne, N., Harding, R. J., \& Essery, R. L. (2002). The Influence of Land Use Change on Climate in the Sahel. Journal of Climate, 15, 3615-3629. http://dx.doi.org/10.1175/1520-0442(2002)015<3615:TIOLUC >2.0.CO;2

Tiwari, R., Murthy, I. K., Killi, J., Kandula, K., Bhat, B. R., Nagarajan, R., ... Ravindranath, N. H. (2010). Land use dynamics in select village ecosystems of southern India: drivers and implications. Journal of Land Use Science, 5(3), 197-215. http://dx.doi.org/10.1080/1747423X.2010.500683

Tol, R. S. J. (1998). Socio-economic Scenarios. In F. Jan, J. F. Feenstra, I. Burton, J. B. Smith, \& R. S. J. Tol (Eds.), Handbook on Methods for Climate Change Impact Assessment and Adaptation Strategies. Version 2.0, UNEP/IVM Handbook.

Verburg, P. H., Eickhout, B., \& Meij, H. (2007). A multi-scale, multi-model approach for analyzing the future dynamics of European land use. Annals of Regional Science.

Wang, G. L., \& Eltahir, E. A. B. (2000). Biosphere-atmosphere interactions over West Africa. II: Multiple climate equilibria. Quarterly Journal of Royal Meteorological Society, 126, 1261-1280. http://dx.doi.org/10.1002/qj.49712656504

Weng, Q. (2002). Land use change analysis in the Zhujiang Delta of China using Satellite remote sensing, GIS and stochastic modelling. Journal of Environmental Management, 64, 273-284. http://dx.doi.org/10.1006/jema.2001.0509

Wilby, R. L., Charles, S. P., Zorita, E., Timbal, B., Whetton, P., \& Mearns, L. O. (2004). Guidelines for use of climate scenarios developed from statistical downscaling methods.

\section{Copyrights}

Copyright for this article is retained by the author(s), with first publication rights granted to the journal.

This is an open-access article distributed under the terms and conditions of the Creative Commons Attribution license (http://creativecommons.org/licenses/by/3.0/). 